\title{
THE REGENSBURG PROTOCOL FOR SPINAL METASTASES
}

\author{
PROTOCOLO DE REGENSBURG PARA METÁSTASES DA COLUNA \\ PROTOCOLO DE REGENSBURG PARA METÁSTASIS DE COLUMNA
}

José Manuel Pérez Atanasio ${ }^{1}$, Carsten Neumann² ${ }^{2}$, Michael Nerlich ${ }^{2}$

\begin{abstract}
Metastases to the vertebrae are a common problem in the practice of a spine surgeon. Therapeutic intervention can alleviate pain, preserve or improve neurologic function, achieve mechanical stability, optimize local tumor control, and improve quality of life. Treatment options available for metastatic spine tumors include radiation therapy, chemotherapy and surgery. This article is focused on the decision making for spine surgeons and shows the protocol to treat spinal metastases at the University Hospital of Regensburg, Germany.
\end{abstract}

Keywords: Protocol; Spinal neoplasms; Neoplasm metastasis.

\section{RESUMO}

As metástases nas vértebras são um problema comum na prática do cirurgião de coluna. A intervenção terapêutica pode aliviar a dor, preservar ou melhorar a função neurológica, obter a estabilidade mecânica, otimizar o controle local do tumor e melhorar a qualidade de vida. As opções de tratamento disponíveis para os tumores metastáticos da coluna vertebral incluem radioterapia, quimioterapia e cirurgia. O foco deste artigo é a tomada de decisão para cirurgiões de coluna, e mostra o protocolo de tratamento de metástases da coluna vertebral no Hospital Universitário de Regensburg, Alemanha.

Descritores: Protocolo; Neoplasias da coluna vertebral; Metástase neoplásica.

\section{RESUMEN}

Las metástasis en las vértebras son un problema común en la práctica de un cirujano de columna. La intervención terapéutica puede aliviar el dolor, mantener o mejorar la función neurológica, lograr la estabilidad mecánica, optimizar el control local del tumor y mejorar la calidad de vida. Las opciones de tratamiento para los tumores de la columna vertebral metastáticos son la radioterapia, la quimioterapia y la cirugía. Este artículo se centra en la toma de decisiones para los cirujanos de columna y muestra el protocolo de manejo de las metástasis vertebrales en el Hospital Universitario de Regensburg, Alemania.

Descriptores: Protocolo; Neoplasias de la columna vertebral; Metástasis de la neoplasia.

\section{INTRODUCTION}

Metastases of the spinal column are a common manifestation of advanced cancer. Severe pain, pathologic fracture, and neurologic deficit due to spinal metastases need adequate treatment. Besides oncologic aspects and quality of life, treatment decisions should also include the survival prognosis. ${ }^{1,2}$

The incidence of skeletal metastases carcinoma is second only to pulmonary and hepatic metastases. ${ }^{3}$ The most frequently affected segment of the skeleton is the vertebral column It is estimated that more that $10 \%$ of tumor patients develop symptomatic spinal metastases. ${ }^{4,5}$ The vertebral bodies are reached largely via the bloodstream and neoplastic substitution of the bone tissue causes progressive structural destruction leading to loss of stability and compression of the spinal neural structures. ${ }^{6}$

Unrecognized or previously untreated vertebral lesions often present with severe pain and bony compromise that may eventually progress to the onset of neurological deficits. The Metastatic spinal cord compression is defined as the compression of the dural sac and its contents by an extradural tumor mass. ${ }^{7}$ Improved oncological outcomes ${ }^{8}$ have resulted in more frequent presentation. ${ }^{9}$ Autopsy data demonstrate spinal metastases in $70 \%$ of the commonest cancers and an the incidence of symptomatic Metastatic spinal cord compression in up to $10 \% .^{10}$

The spinal metastases may not only be the cause of severe de- terioration in the quality of life, but also the direct or indirect cause of death. Metastases to the spine represent a challenging problem in a spine surgeon practice. Treatment decisions require multidisciplinary review. Radiation therapy remains the primary treatment for metastatic spinal tumor, but advances in chemotherapy and surgery have changed the roles of each and lead to improved patient outcomes. Regardless of the treatment, diagnosis and treatment before the development of significant neurologic and functional deficits improve outcomes. All patients showing prolonged back pain having a history of cancer have to be evaluated for spinal metastases.

The University Hospital Regensburg ${ }^{11}$ has become one of the most modern as well as one of the most efficient hospitals in Germany since its establishment in 1992. Is the only tertiary health care provider in Eastern Bavaria, a region with about 2 Million inhabitants. About 30,000 in-patients and 110,000 out-patients are treated here every year.

This Hospital has 833 beds and 40 day clinic treatment places and employs more than 3,500 members of staff: over 550 physicians and more than 1.000 nurses. The hospital accommodates 23 different departments and institutions as well as 6 clinical-theoretical institutes on a gross floor space of about 65,000 sqm.

Through the joint effort of the University of Regensburg, the Medical Faculty and the University Hospital, Regensburg has become the second-largest center for biotechnological research and development in Bavaria; in table 1 is shown the characteristics of the Regensburg University Medical Center.

1. Department of Emergency, General Hospital Number 68 National Mexican Institute for Social security (IMSS), State of Mexico, Mexico.

2. Department of Trauma and Orthopaedic Surgery, Regensburg University Medical Center, Germany. 
Table 1. Characteristics of the Regensburg University Medical Center

\begin{tabular}{c|c}
\hline Members of staff & Approximately $\mathbf{3 . 5 0 0}$ \\
\hline Students & About 1.800 medical and dental students \\
\hline Health care level & 3 (tertiary care) \\
\hline Catchment area & $\begin{array}{c}\text { 2 Mill. inhabitants of Eastern Bavaria (Districts of } \\
\text { Upper Palatinate and Lower Bavaria) }\end{array}$ \\
\hline Current capacity & 833 beds, 40 day clinic treatment places \\
\hline \multirow{2}{*}{ Performance data 2010 } & Out-atients:112.179 \\
\cline { 2 - 2 } & In-patients: 30.659 \\
\cline { 2 - 2 } & Average length of stay: 8,13 days \\
\hline
\end{tabular}

Regensburg is the leading German university hospital and thus the most efficient tertiary health care provider in Germany.

Pathway for decision making

This pathway for decision making represent the form to treat patients with spinal metastases at the University Hospital of Regensburg, Germany and is synthesized in Figure 1.

The final way to treat patients in different medical centers around the world will depends on the infrastructure, facilities of implants, law conditions and the decision to use a particular surgical approach will be determine for the location of the bone, epidural, and paraspinal tumor, type of reconstruction required, patient comorbidities, extent of disease, and surgeon's familiarity.

Before the surgical treatment of patients with spinal metastases is important to consider that the patient must be on control for the oncology and orthopedic departments. The first step is to try to identify the primary tumor with a biopsy and histological diagnostic unless the patients shows acute onset of a neurologic deficit.

Radiotherapy has been the primary therapy for managing metastatic spinal disease; however, surgery that decompresses the spinal cord circumferentially, followed by reconstruction and immediate stabilization, has also proven effective. ${ }^{12}$ One systematic review suggests that surgical excision of tumor and instrumented stabilization may improve clinical outcomes compared with radiation therapy alone, with regard to neurological function and pain. ${ }^{13}$

According with the type of primary tumors, tumors from Lung, digestive system (stomach, gut, liver, etc.) and melanoma usually have an aggressive behavior and bad prognosis (median life expectance with spinal metastases less than 6 months) in the other hand tumors from Breast, prostate, kidney and multiple myeloma usually have a relative good behavior (more than 2 years medial survival) and better response to oncologic treatment.

Is useful to classify the metastases with some score ${ }^{2}$ like

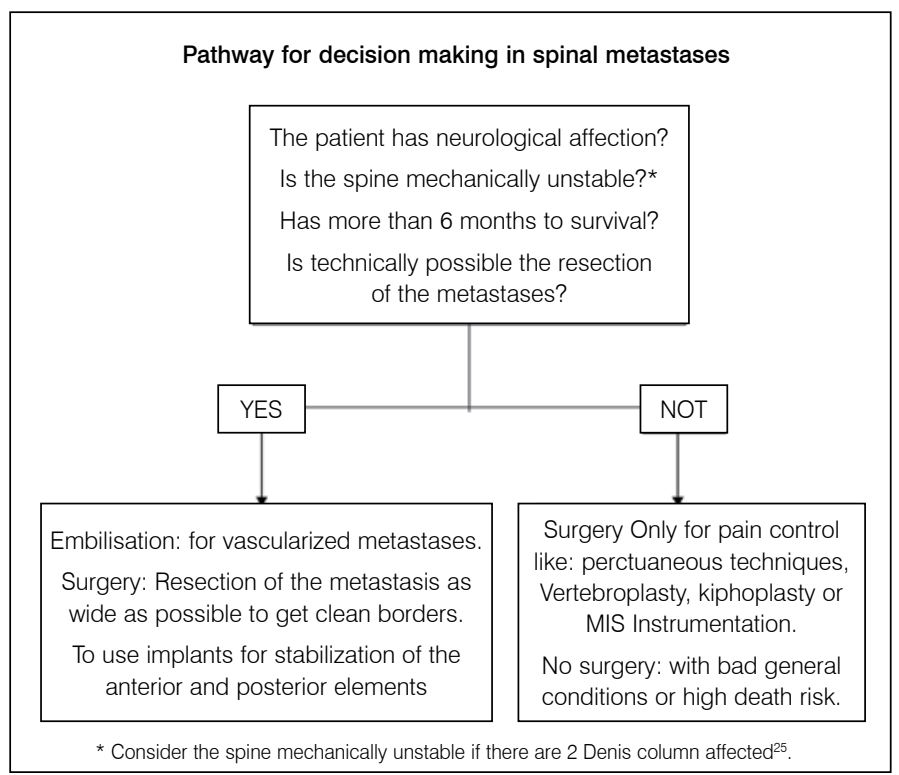

Figure 1. Pathway for decision making in spinal metastases used at the University Hospital of Regensburg, Germany.
Tokuhashi et al. ${ }^{14-16}$ or Tomita score, ${ }^{17,18}$ and for the surgical treatment is necessary to identify if there are spine instability or neurological affection and to determine the survival probability.

Given that the reported surgical complication rate is between $20 \%$ and $30 \%,{ }^{19,20}$ risks must be carefully balanced against the potential benefits when deciding the preferred treatment in order to maximise the quality of remaining life.

When surgery is considered in the treatment is important to do a Resection of the metastasis as wide as possible to get clean borders.

Vertebroplasty and kyphoplasty are among the most commonly used treatments for axial mechanical pain secondary to vertebral osteolysis or compression fractures. Prospective studies have demonstrated effective pain relief and satisfactory functional outcomes. ${ }^{21,22}$

The patients must have information about the surgery benefits and risks and sign a letter to approve the treatment. Is important to continue the oncologic management with radiation after surgery and additional chemotherapy if possible. ${ }^{23}$ Is useful to know diferents protocols. ${ }^{24}$ All patients need psychologic attention.

\section{Case}

This case is presented to show how the pathway for decision making is used.

Case: Woman of 37 years old with breast primary tumor and presents metastases in the T8 vertebral body. Have pain of 10 in the visual analogue scale. Without neurological impairment. The Xray, Tomographic and gammagraphy views are shown in Figures 2, 3 and 4.

According with the pathway for decision making the spine surgeon made the next questions: The patient has neurological affection? Is the spine mechanically unstable?

Has more than 6 months to survival? Is technically possible the resection of the metastases? Answer: Yes. So the treatment was: Surgery with a posterior approach, resection of the vertebral body
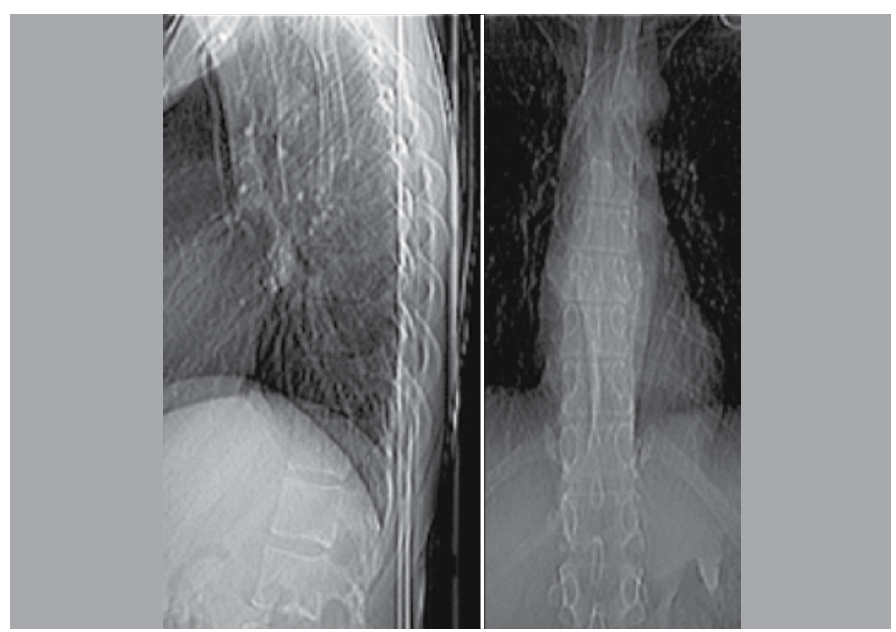

Figure 2. Xray view of thoracic spine.

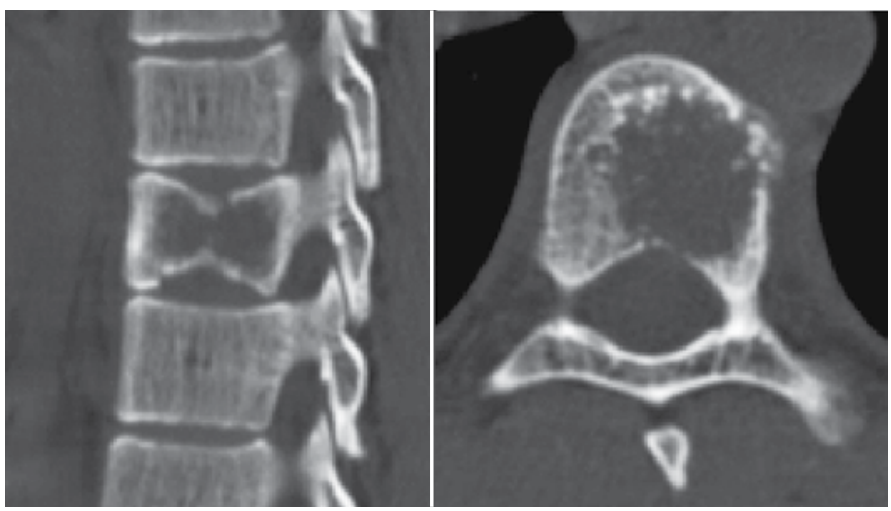

Figure 3. Tomographic view of thoracic spine, vertebral body of T8 is affected. 
of T8 affected for the metastases in order to decrease the tumoral mass train to have clean borders, in Figure 5 we can see an trans operative view. To obtain stability was used posterior instrumentation with transpedicular screws and anterior support with a vertebral body supply. In figure 6 is shown the $x$ ray view of the surgical result.

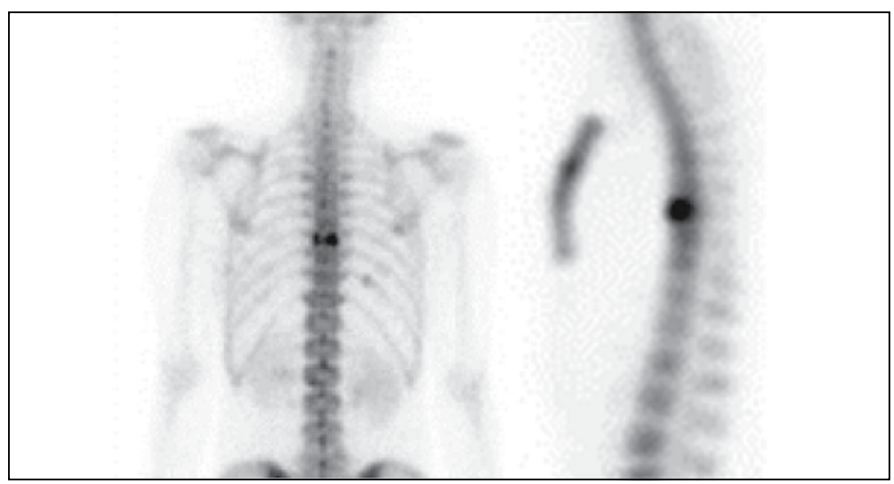

Figure 4. Gammagraphy of the thoracic spine.

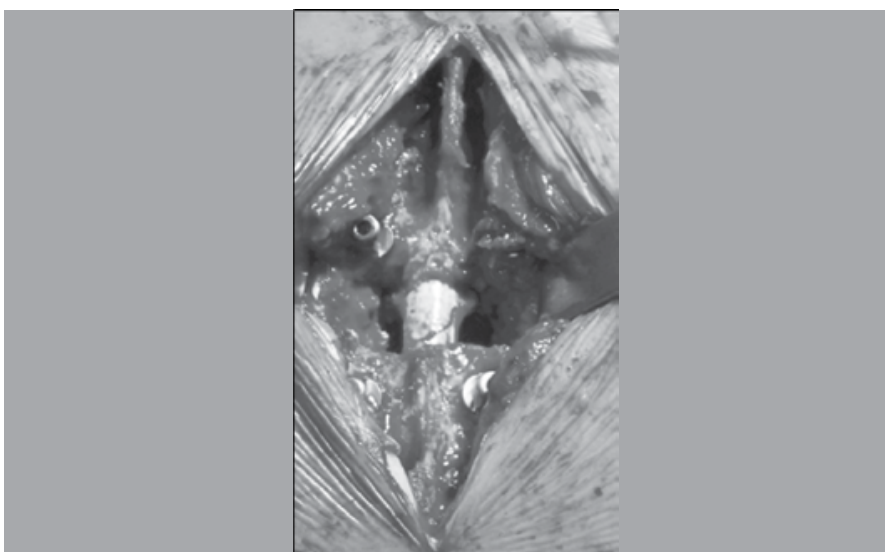

Figure 5. Trans operative view showing the complete resection of the T8 vertebra, was necessary to cut the nerve roots.

\section{REFERENCES}

1. Bilsky MH, Lis E, Raizer J, Lee $H$, Boland P. The diagnosis and treatment of metastatic spinal tumor. Oncologist. 1999:4(6):459-69.

2. Wibmer $\mathrm{C}$, Leithner $\mathrm{A}$, Hofmann G, Clar H, Kapitan M, Berghold A, et al. Survival analysis of 254 patients after manifestation of spinal metastases: evaluation of seven preoperative scoring systems. Spine (Phila Pa 1976). 2011;36(23):1977-86.

3. Hosono N, Yonenobu K, Fuji T, Ebara S, Yamashita K, Ono K. Orthopaedic management of spinal metastases. Clin Orthop Relat Res. 1995;(312):148-59.

4. Harrington KD. Orthopedic surgical management of skeletal complications of malignancy. Cancer. 1997:80(Suppl 8):1614-27.

5. Sundaresan N, Digiacinto GV, Hughes JE, Cafferty M, Vallejo A. Treatment of neoplastic spinal cord compression: results of a prospective study. Neurosurgery. 1991;29(5):645-50.

6. Gasbarrini A, Cappuccio M, Mirabile L, Bandiera S, Terzi S, Barbanti Bròdano G, et al. Spinal metastases: treatment evaluation algorithm. Eur Rev Med Pharmacol Sci. 2004:8(6):265-74.

7. Loblaw DA, Laperriere NJ, Mackillop WJ. A population-based study of malignant spinal cord compression in Ontario. Clin Oncol (R Coll Radiol). 2003;15(4):211-7.

8. Brenner $\mathrm{H}$, Gondos $\mathrm{A}$, Arndt V. Recent major progress in long-term cancer patient survival disclosed by modeled period analysis. J Clin Oncol. 2007;25(22):3274-80.

9. Hatrick NC, Lucas JD, Timothy AR, Smith MA. The surgical treatment of metastatic disease of the spine. Radiother Oncol. 2000;56(3):335-9.

10. Ibrahim A, Crockard A, Antonietti P, Boriani S, Bünger C, Gasbarrini A et al. Does spinal surgery improve the quality of life for those with extradural (spinal) osseous metastases? An international multicenter prospective observational study of 223 patients. Invited submission from the Joint Section Meeting on Disorders of the Spine and Peripheral Nerves, March 2007. J Neurosurg Spine. 2008:8(3):271-8.

11. University Hospital Regensburg. Disponível em: www.uniklinikum-regensburg.de

12. Klimo P Jr, Thompson CJ, Kestle JR, Schmidt MH. A meta-analysis of surgery versus conventional radiotherapy for the treatment of metastatic spinal epidural disease. Neuro Oncol. 2005;7(1):64-76

13. Kim JM, Losina E, Bono CM, Schoenfeld AJ, Collins JE, Katz JN, et al. Clinical outcome of metastatic spinal cord compression treated with surgical excision \pm radiation versus radiation therapy alone: a systematic review of literature. Spine (Phila Pa 1976). 2012;37(1):78-84.

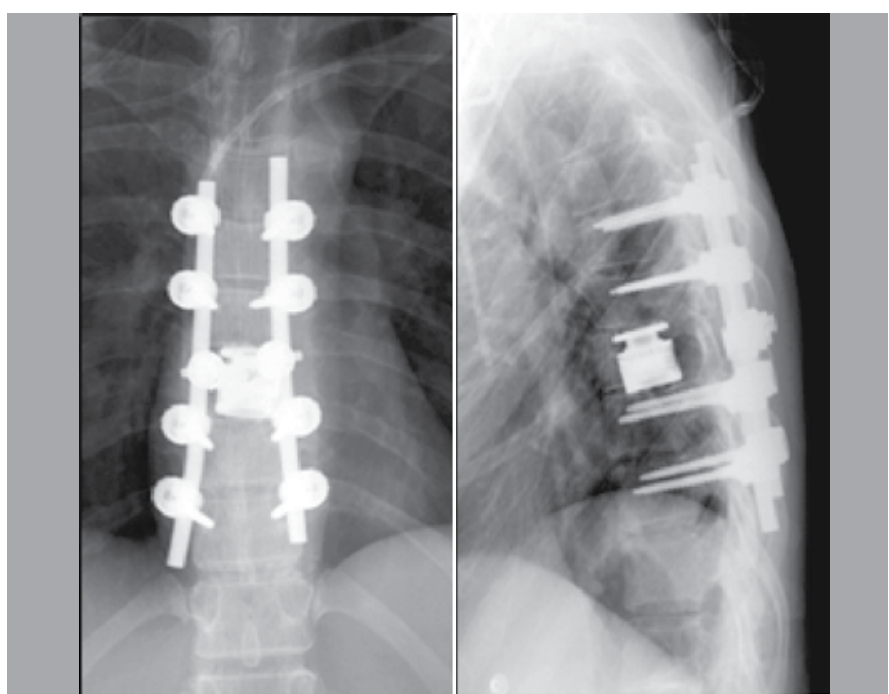

Figure 6. Xray view of postoperative.

\section{CONCLUSIONS}

Spinal metastases are a big challenge for spine surgeons. The surgery treatment must be individualized according with the general conditions of the patient, the neurological deficit, spine instability, rate of survival. The local infrastructure will also affect the decision. This article describes a pathway for spinal metastases in order to help spine surgeons in the decision making. The final objective is to improve the quality of life of the patients with spinal metastases.

\section{ACKNOWLEDGEMENTS}

We would like to thank to The Orthopaedic Department of the University Hospital of Regensburg for their hospitality and friendship.

All authors declare no potential conflict of interest concerning this article.

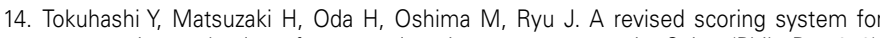
preoperative evaluation of metastatic spine tumor prognosis. Spine (Phila Pa 1976). 2005:30(19):2186-91.

15. TokuhashiY, Ajiro Y, Umezawa N. Outcome of treatment for spinal metastases using scoring system for preoperative evaluation of prognosis. Spine (Phila PA 1976). 2009;34(1):69-73.

16. Tokuhashi Y, Matsuzaki H, Toriyama S, Kawano H, Ohsaka S. Scoring system for the preoperative evaluation of metastatic spine tumor prognosis. Spine (Phila Pa 1976). 1990;15(11):1110-3.

17. Tomita K, Kawahara N, Kobayashi T, Yoshida A, Murakami H, Akamaru T. Surgical strategy for spinal metastases. Spine (Phila Pa 1976). 2001:26(3):298-306.

18. Ulmar B, Naumann U, Catalkaya S, Muche R, Cakir B, Schmidt R, et al. Prognosis scores of Tokuhashi and Tomita for patients with spinal metastases of renal cancer. Ann Surg Oncol. 2007;14(2):998-1004.

19. Sundaresan N, Choi IS, Hughes JE, Sachdev VP, Berenstein A. Treatment of spinal metastases from kidney cancer by presurgical embolization and resection. J Neurosurg. 1990;73(4):548-54

20. Cooper PR, Errico TJ, Martin R, Crawford B, DiBartolo T. A systematic approach to spinal reconstruction after anterior decompression for neoplastic disease of the thoracic and lumbar spine. Neurosurgery. 1993;32(1):1-8.

21. Cahana A, Seium Y, Diby M, Martin JB, Ruefenacht D, Dietrich PY. Percutaneous vertebroplasty in octogenarians: results and follow-up. Pain Pract. 2005:5(4):316-23.

22. Pflugmacher R, Kandziora F, Schroeder RJ, Melcher I, Haas NP, Klostermann CK. Percutaneous balloon kyphoplasty in the treatment of pathological vertebral body fracture and deformity in multiple myeloma: a one-year follow-up. Acta Radiol. 2006;47(4):369-76.

23. Tanaka M, Nakahara S, Ito Y, Kunisada T, Misawa H, Koshimune K, et al. Surgical treatment of metastatic vertebral tumors. Acta Med Okayama. 2009;63(3):145-50.

24. Siddique I Stirling AJ The surgical management of metastatic spinal cord compression. J Bone Joint Surg. [online]. 2010;1-5. Available from URL: http://www. http://www.boneandjoint.org.uk/content/focus/surgical-management-metastatic-spinal-cord-compression

25. Denis F. The three column spine and its significance in the classification of acute thoracolumbar spinal injuries. Spine (Phila Pa 1976). 1983;8(8):817-31. 